\title{
Comunicación

\section{La correspondencia entre función comunicativa y función semántica en los manuales de instrucciones}

\author{
VERÓNICA VIVANCO CERVERO*
}

El objeto del presente estudio es el esclarecimiento de las divisiones temáticas y las funciones comunicativas inherentes a los manuales de instrucciones de electrodomésticos, un tipo de literatura que constituye un género propio. Los movimientos que salen a la luz son siete: advertencias, características técnicas, instalación, funcionamiento, limpieza y mantenimiento, solución de problemas y, finalmente, garantía y servicio técnico. Estos se acoplan con diversas funciones semánticas que oscilan desde el consejo, la precaución y la información (inicio), atraviesan la función explicativa en los movimientos centrales del manual de instrucciones, y acaban en el mensaje informativo de la parte final, marcando, así, la progresión lógica del texto.

PALABRAS CLAVE: manuales de instrucciones, comunicación, semántica, explicación, información.
The object of the present paper is the outlining of the thematic divisions and the communicative functions inherent to the genre of instructional household appliance leaflets. The movements that come to light are warning, technical specifications, preparation for use, use, cleaning and maintenance, troubleshooting, and finally, guarantee / warranty and technical service. The aforementioned movements match with different semantic functions that range from advice, caution and information (first part), to the explanatory function in the middle movements, and to the informative message in the final part, signalling, in this way, the progression of the text.

KEY WORDS:instruction manuals, communication, semantics, explanation, information.

* Universidad Politécnica de Madrid, España.

Correo electrónico: veronicavivancocervero@yahoo.es 


\section{EL GÉNERO COMO ACTO COMUNICATIVO}

Este artículo tiene como objetivo esbozar los tipos de funciones comunicativas y semánticas que competen a los diferentes movimientos de los textos instruccionales referidos al manejo y funcionamiento de electrodomésticos. Consideramos funciones semánticas a los actos del habla, su significado y, también, a los elementos que los apoyan, tales como las indicaciones de propósito, condición, temporalidad, etc. El término "semántica", tomado en el sentido amplio de "ciencia del significado", engloba a la pragmática, disciplina que surge de los espacios que se le escapan a la primera. La pragmática estudia actos de habla comunicativos desde la interpretación y la crítica de los procesos sociales y psicológicos, por lo que implica un conjunto de reglas de expresión dentro de un contexto. La producción o codificación del discurso, desde una perspectiva pragmática, constituye actos de habla específicos en situaciones específicas: se intenta, así, la interacción con terceras partes a través de la intencionalidad. De ahí se llega al consumo o descodificación, del discurso.

Los mencionados textos instruccionales conforman un tipo de género, denominación que coincide con la de tipología textual o tipo de texto (Bailar et al. 1984; Álvarez-Dardet et al. 1987:296-301).

La clasificación de los diferentes tipos de textos procedentes de entornos profesionales y académicos se conoce en la actualidad como género. Las convenciones formales y estilísticas a las que se atienen los géneros son la función comunicativa y semántica, aspecto que abordaremos en las siguientes líneas, seguimiento de un esquema conocido como macroestructura, que desarrolla una modalidad discursiva con estructuras léxicas y sintácticas entrelazadas con unas ciertas convenciones sociopragmáticas. El concepto de función comunicativa se refiere al contenido del mensaje, pudiendo abarcar éste desde el manejo básico de un aparato hasta su reparación. La función semántica se solapa sobre la anterior y proporciona al mensaje un significado que se apoya en una modalidad lingüística informativa, prescriptiva, etc.

Las características de los géneros son la situación comunicativa y profesional, la dualidad social y profesional, la pertenencia a una comunidad, el engarce de forma y contenido y el dinamismo retórico. 
Esto último consiste en la división de un texto en fases de funciones específicas para llegar a un fin.

El concepto de género realmente surgió de un ahondamiento en el estudio discursivo, a través de la delimitación de macro y microestructuras que facilitan la elaboración y comprensión del discurso propio de cada comunidad profesional y cognitiva: en el caso concreto de los manuales de instrucciones, nos encontramos ante un doblete en el proceso emisor-receptor, ya que el mensaje parte de técnicos especialistas en electrodomésticos y llega al consumidor final, grupo que se compone de un amplio espectro de legos y no legos en la materia. Los elementos constitutivos del género como acto comunicativo comparten una finalidad: la transmisión de un mensaje claro, y conducen a través de un proceso gradual a una conclusión, el funcionamiento de un electrodoméstico. Sin embargo, lo que resulta claro para el técnico que produce el mensaje instruccional puede no serlo para el receptor, quien puede realizar inferencias correctas o no.

También pensamos que una mínima alteración puede dar lugar a un subgénero específico que no conlleva necesariamente un cambio estructural, sino de contenido y escala axiológica (Vivanco, 2001). El género, por lo tanto, es un evento comunicativo altamente estructurado y convencional que, en consecuencia, impone unas ciertas limitaciones a las que es obligado atenerse. No obstante, los conocedores de estas convenciones las usan con un mayor grado de soltura y creatividad que los ajenos a ellas.

\section{LAS FUNCIONES SEMÁNTICAS}

DE LOS MANUALES DE INSTRUCCIONES

Los textos instruccionales son a la vez informativos, explicativos (en ellos prima la función referencial) y prescriptivos. Los manuales de instrucciones suelen ser textos sencillos y prácticos en su estilo desprovisto de ornamentación, constituyendo la terminología de especialidad la única nota oscura con respecto a la comprensión del mensaje.

En el análisis del discurso existen tres elementos funcionales, cuyo estudio se ha investigado con profusión (Carroll y Delin 1998; Ciliberti 1990; Delin et al. 1994, 1996; Murcia 2000; Murcia y Delin 2001; Paris y Scott 1994; Puglielli, 1990) en torno a los textos de instrucciones: 
- Informativo: el mensaje proporciona información al lector:

El JMF 1020 puede recargar simultáneamente de 1 a 20 baterías.

- Consejo: el mensaje aconseja al lector realizar o no realizar una acción:

Es conveniente mantener iluminada la habitación.

- Propósito: el mensaje le explica al lector cómo realizar una acción:

Para conectar las baterías, usted debe...

Los dos primeros ejemplos son casos de actos del habla, mientras que el tercer caso apoya un acto del habla, elementos que conjuntamente se pueden agrupar bajo el denominador común de funciones semánticas. Pero los textos instruccionales además de ofrecer consejo, información y explicar el método para lograr un fin, necesitan herramientas adicionales para resultar funcionales y cuyo discernimiento va a ser el objeto de las siguientes líneas.

La recolección de datos para el estudio se ha realizado a partir de 50 textos instruccionales publicados en lengua española con diferente longitud y autoría, pero todos ellos pertenecientes al ámbito de las instrucciones en el manejo de electrodomésticos. Los textos instruccionales proceden de electrodomésticos del hogar, tanto grandes (neveras [refrigeradores], lavadoras, televisión, etc.) como pequeños (impresoras, pesos, cargadores de juegos infantiles, planchas, depiladoras, despertadores aparatos de masaje, etc.).

Las funciones semánticas de los textos instruccionales se han dividido en actos del habla, unidades de apoyo, título, dirección y mensaje fático. Estos tres últimos elementos aparecen en todos los manuales de instrucciones, marcando, respectivamente, el inicio del mensaje y la finalidad del manual (el título Máquinas para cargar baterías se divide respectivamente en Preparación de las baterías, La conexión de las baterías, y, finalmente, La regeneración de las baterías), la dirección de la empresa para cualquier consulta o reclamación, y un mensaje de comunicación más personal con el cliente de la empresa (Estimado usuario I cliente, Enhorabuena ha decidido adquirir un producto de alta calidad de la marca Korona, Gracias, u otras formas de acercamiento al comprador, como Estamos a su disposición para cualquier pregunta, y le recordamos exportamos también todo el material necesario para el reacondicionamiento de baterías y que podemos asegurar su formación 
técnica en cualquier país.). Este tipo de mensajes se construye mediante estrategias de oralidad, por lo que simulan un diálogo entre el emisor y el receptor del mensaje (Raible, 2004).

En relación con los actos del habla, además de los mencionados y objeto de profusas investigaciones anteriores (Murcia y O'Donnell 2002), los textos instruccionales revelan diversos tipos de funciones:

- Precaución ( advertencia en el sentido de no realización de una acción): Si se avería, debemos avisar al técnico, no realizando nosotros aquellas tareas para las que no estamos autorizados, ni formados. Nunca manipular.

- Prohibición: Está prohibido efectuar fotocopias con la tapa de la máquina sin cerrar totalmente, por el impacto de la luz sobre los ojos.

Otros tipos de funciones son las siguientes:

- Condición: (Si la caja tiene alguna grieta leve...)

- Temporal: (Después de 12 horas...)

- Consecuencia: (..., lo que dañará el equipo y sus sellos)

- Localización: (Girar la rueda de control hacia la derecha ...)

- Modo: (... de manera que la regulación no tiene efecto sobre el espesor)

- Instrumentación: (... utilizando este instrumento)

- Razón: (...por este motivo)

- Explicación: (Se dispone de cables con varias longitudes. Eso es únicamente para poder disponer las baterías según el espacio de trabajo que tiene).

\section{EL ENGARCE DE LAS FUNCIONES SEMÁNTICAS EN TEXTOS INSTRUCCIONALES}

Conviene reseñar que algunas de las mencionadas cláusulas, y muy en especial las de condicional, se enlazan con la función de consejo:

Si esto último ocurre deben tomarse consideraciones especiales... G

En caso que el suministro de agua pueda fallar deberá instalarse algún dispositivo de aviso... SE

Si se avería, debemos avisar al técnico... RVICIO 
Asimismo, la función de consejo puede realizarse tanto por medio de una oración declarativa del tipo se aconseja o usted debe ( modal deóntico o de necesidad ), como por medio de un imperativo de función exhortativa (Garrido, 1999:390) o de un infinitivo (Alarcos, 1994: 150) lo que marcaría el contraste entre el modo formal o coloquial de acercamiento al cliente:

Para conectar las baterías, usted debe tomar el conector positivo (+) del JMF (pinza roja) y enchufarlo.

La tapa de la máquina debe de estar totalmente cerrada.

Asegúrense de que el JMF 1020 esté apagado.

Usar guantes para cambiar el tóner.

Repetir esta operación hasta la ultima batería..

Torres (2003:139-146) señala la presencia de la existencia de una modalidad objetiva que a veces contrasta con la subjetiva en los textos de especialidad marcada, en ocasiones, por el verbo deber y por las formas de futuro. Los gerundios también ayudan a producir la impresión de simultaneidad con respecto al verbo principal. Así, como indica Fernández Lagunilla (2000:3447), los mencionados gerundios modificadores "expresan una acción secundaria que se une a la acción denotada por el verbo principal, constituyendo un solo evento":

...utiliza la mejor resolución mejorando así el aspecto de una línea e indicando que está correcta. (modalidad subjetiva)

Esta opción es válida con una tarjeta CGA. (modalidad subjetiva)

...lo que le permitirá manejar fácilmente otros lenguajes. (modalidad subjetiva)

Para situar el programa debe seleccionarse la opción SET Main Module. (modalidad objetiva)

Al sistema de acceso a través de menús se accederá presionando las teclas $<$ Shift $>y<F 1>$ simultáneamente. (modalidad objetiva)

Ya que la función informativa también existe en los textos instruccionales (Mercado, 2003:93-110) el presente de indicativo es un tiempo que aparece con profusión (una batería hinchada indica que ...) y cuya 
presencia se puede alternar con el infinitivo de obligación con valor de imperativo (averiguar el estado de la caja), el imperativo (Asegúrense de que ...) y la pasiva refleja (Se toma ...).

\section{LA CORRESPONDENCIA ENTRE \\ FUNCIÓN SEMÁNTICA Y FUNCIÓN COMUNICATIVA}

En las siguientes líneas trataremos de perfilar los movimientos que estructuran los manuales de instrucciones, así como las funciones comunicativas y semánticas inherentes a cada uno de los movimientos. El primer paso en el bosquejo de movimientos consiste en dar cuenta de los apartados principales, y del orden que éstos siguen en los folletos de instrucciones. Para ello hemos esbozado el orden más habitual en los 50 manuales de instrucciones con los que hemos trabajado.

Cabe señalar que no todos los apartados figuran en todos los manuales. Los apartados de Instalación y Preparación o montaje del electrodoméstico sólo aparecen en los manuales de grandes electrodomésticos, mientras que los dedicados a Recarga de baterías y Conexión a la red se centran en los pequeños electrodomésticos, mientras que Programación aparece en aplicaciones específicas como vídeos, DVDs, relojes despertadores, etc. Otros apartados aparecen indistintamente en posición inicial o final como, por ejemplo, Advertencias, Garantía y Servicio técnico, partes que también pueden figurar en un folleto o en una hoja independiente.

Siete bloques de movimiento salen a la luz, fruto de la observación del corpus. El esquema que sigue muestra los variados movimientos que pueden incorporar uno o más apartados, y sus respectivas funciones comunicativa y semántica.

\section{Movimiento 1}

Función comunicativa: avisar de las precauciones en el uso de la máquina.

Función semántica: consejo

Apartados incluidos: advertencias

\section{Movimiento 2}

Función comunicativa: enumerar los datos técnicos del electrodoméstico. 
Función semántica: informativa

Apartados incluidos: Características técnicas Movimiento 3

Función comunicativa: explicar los datos básicos de la preparación del aparato.

Función semántica: prescriptiva - explicativa

Apartados incluidos: instalación / montaje del electrodoméstico.

Movimiento 4

Función comunicativa: detallar el manejo del electrodoméstico

Función semántica: prescriptiva - explicativa

Apartados incluidos: funcionamiento

Movimiento 5

Función comunicativa: explicar cómo cuidar el aparato para prolongar su duración.

Función semántica: prescriptiva - explicativa

Apartados incluidos: limpieza y mantenimiento

Movimiento 6

Función comunicativa: explicar el modo de solventar las irregularidades potenciales que pueden surgir en el comportamiento del electrodoméstico.

Función semántica: prescriptiva - explicativa

Apartados incluidos: solución de problemas

\section{Movimiento 7}

Función comunicativa: advertir al consumidor de las condiciones establecidas para la reparación del aparato y ofrecer los canales para su reparación.

Función semántica: informativa

Apartados incluidos: garantía y servicio técnico

El movimiento 1, Advertencias, que en ocasiones recibe el título de Importante o Precauciones de uso, persigue avisar a los clientes de los posibles riesgos del manejo erróneo del aparato en cuestión, de dejarlo al alcance de niños, en temperaturas extremas, bajo la exposición al sol, etc.

En el movimiento denominado Advertencias, priman las funciones semánticas de consejo, precaución (en el sentido de no realización de 
una acción) y prohibición. En el ejemplo 1 se muestran en concreto las dos primeras funciones. La forma de precaución No usen aconseja sobre los casos concretos en que el consumidor debe abstenerse de utilizar el aparato. Del mismo modo, la fórmula No presionen va acompañada en la siguiente oración del motivo para la ausencia de tal proceder ( $E l$ uso de Visapure siempre debe resultar agradable).

Asimismo, existen otras formas verbales en el primer movimiento de los manuales instruccionales que siguen un modelo de consejo positivo en imperativo de cortesía, futuro y presente de indicativo: Tengan en cuenta, deberán reducir, debe resultar, Mantengan el aparato fuera del alcance de los niños, Usen, Cuando usen... asegúrense, fórmula que enlaza la función semántica de temporalidad con la de consejo. También la expresión duración más corta de la recomendada habitualmente une consejo y razón o motivo (La zona del escote es más sensible que la cara). Sin embargo, las oraciones de función semántica puramente informativa también aparecen en el apartado de advertencias, como podemos ver en El aparato es impermeable y puede usarse en la ducha.

\section{Ejemplo 1}

- No usen Visapure sobre piel seca o agrietada o cuando padezcan enfermedades o irritaciones de la piel tales como acné, quemaduras solares, etc.

- Tengan en cuenta que la condición de la piel varía a lo largo del año. La piel facial puede estar más seca durante el periodo invernal y, por lo tanto, deberán reducir la duración del tratamiento.

- No presionen el cepillo demasiado fuerte sobre la cara. El uso de Visapure siempre debe resultar agradable.

- Cuando usen Visapure sobre el escote, asegúrense que siguen una duración del tratamiento más corta de la recomendada normalmente. La zona del escote es más sensible que la cara.

- Una limpieza regular del aparato asegura unos resultados óptimos y una vida útil más larga.

- Mantengan el aparato fuera del alcance de los niños.

- Usen, por ejemplo, una cinta para el pelo para mantener su cabello lejos de la cara a fin de evitar que se enrede en el cepillo.

- El aparato es impermeable y puede usarse en la ducha. 
El movimiento 2 se compone del apartado llamado Características técnicas. Nuestra opinión es que los diversos epígrafes que pueden aparecer en este apartado tienen por objetivo la descripción técnica general del aparato. Este movimiento puede incorporar un diagrama, dibujo o esquema del electrodoméstico en cuestión, que aclare la ubicación de cada uno de los componentes del equipo y que, por medio de una enumeración, enlace la terminología técnica con un gráfico.

El movimiento llamado Características técnicas suele ser el más parco en desarrollo oracional. Su función semántica es meramente informativa, absteniéndose de emitir consejos, condiciones, modalidad, etc.

\section{Ejemplo 2}

Especificaciones técnicas

Fuentes de alimentación

CA:

230-240 V- $50 \mathrm{~Hz}$ (estándard CE)

110-120 V- $60 \mathrm{~Hz}$ (otros estándares)

Baterías: 4 x UM-1 (D, LR 20 o equivalente)

Consumo: $8 \mathrm{~W}$

Potencia: $550 \mathrm{~mW}$ máximo

Gama de frecuencias de radio

FM:

$88-100 \mathrm{MHz}$

AM:

$540-1600 \mathrm{kHz}$

Sistema de grabación:

Sistema de grabación

Polarización DC

Sistema de borrado

Borrado magnético

General

Auriculares:

Clavija estéreo de $3.5 \mathrm{~mm}, 8-32$ megas

Dimensiones:

(L x A x A) $300 \times 135 \times 112 \mathrm{~mm}$

El movimiento 3 describe la instalación o montaje del electrodoméstico, así como la recarga de baterías, el modo de conexión a la red o la programación del aparato en cuestión, es decir los prolegómenos al manejo de la máquina, motivo por el que hemos englobado los diversos apartados en un mismo movimiento. Los mencionados epígrafes son, junto con el de Funcionamiento, los movimientos más leídos en los manuales de instrucciones. 
El tercer movimiento de los folletos instruccionales, Instalación y montaje, se suele encontrar plagado de imperativos que, más que enlazar con la función semántica de consejo, apuntan hacia lo prescriptivo-explicativo por medio de instrucciones breves y precisas que siguen un orden cronológico en la enumeración de los pasos a seguir: Asegúrese, Si no fuera así espere, pulse, espere, entonces pulse... y seleccione, pulse, seleccione, indique, etc. Las mencionadas explicaciones se complementan con notas de acompañamiento de corte informativo, como Durante este proceso aparece un " 8 " de manera intermitente, y otras de propósito, como Para programar otro espacio de memoria, repita los pasos 1-7.

\section{Ejemplo 3}

Programación de la báscula

Asegúrese de que la báscula se encuentre en modo de reserva y que la pantalla no muestre ningún valor o símbolo. Si no fuera así, espere unos segundos hasta que la pantalla se haya apagado de manera automática.

Paso 1: pulse ligeramente la báscula y espere hasta que aparezca indicado " $0.0 \mathrm{Kg}$ ". Durante este proceso aparece un " 8 " de manera intermitente.

Paso 2: entonces pulse la tecla "Set" y seleccione con las teclas de flechas cada uno de los espacios de memoria que desee programar.

Paso 3: pulse la tecla "Set".

Paso 4: aparecen con luz intermitente los símbolos de "masculino" y "femenino".

Paso 5: seleccione el sexo con la ayuda de la flecha izquierda y pulse la tecla "Set".

Paso 6: con las teclas de flechas indique ahora el tamaño. Finalizado el ajuste, vuelva a pulsar la tecla "Set".

Paso 7: indique la edad. Vuelva a utilizar las flechas para seleccionar su edad. Finalmente, pulse la tecla "Set". Ha finalizado la programación del espacio de memoria.

Para programar otro espacio de memoria, repita los pasos 1-7.

El movimiento 4 se refiere a las Instrucciones de uso en sí, por lo que dicho movimiento, conocido también como Funcionamiento o $\mathrm{Ma}$ nejo, constituye el mensaje central del manual, junto con el referido a 
los prolegómenos del funcionamiento. En ocasiones las instrucciones de uso se dividen en fases de avance cronológico o en clasificaciones según el modo de uso, como en el ejemplo que sigue.

El movimiento de Instrucciones sigue un patrón prescriptivo-explicativo en el que se describe el modo de actuación en el manejo del electrodoméstico: Enchufe, coloque, asegúrese, llene, pulse, etc. El movimiento se completa con mensajes que conllevan la función semántica de propósito (para que de esta forma vuelva a su posición inicial de planchado con vapor) o de consecuencia (y la plancha comenzará a generar vapor al ponerla totalmente horizontal).

\section{Ejemplo 4}

Funcionamiento del planchado en seco

Enchufe la plancha y coloque el selector de temperatura en la posición deseada. Cuando la plancha alcance la temperatura elegida el piloto se apagará. Si el depósito tiene agua, asegúrese de que el botón de vapor esté pulsado (posición en seco).

\section{Funcionamiento del planchado con vapor}

Con la plancha desenchufada, llene el depósito de agua mediante el vaso de plástico que se suministra con ella, respetando el nivel máximo indicado. Coloque el selector de temperatura en la posición para planchar con vapor y el botón de vapor pulsado en la posición de planchado en seco. Cuando el piloto de funcionamiento se apague, pulse el botón de vapor, para que de esta forma vuelva a su posición inicial de planchado con vapor y la plancha comenzará a generar vapor al ponerla totalmente horizontal.

Para interrumpir la formación de vapor, basta colocar la plancha en posición vertical o pulsar el botón de vapor en posición de seco.

El movimiento 5 incluye los apartados de limpieza y mantenimiento, con el fin de garantizar la durabilidad del producto, y puede incluir una breve nota sobre las precauciones relativas al proceso de limpieza, como pueden ser la desconexión del aparato.

El movimiento de Limpieza y mantenimiento también es prescriptivo-explicativo pero se encuentra restringido por limitaciones temporales (Después del lavado revise, Cuando sea necesario podéis) o 
condicionales (límpielo si hay restos de detergente, podéis limpiar ... si dentro de ella están ...). De este modo se conjugan las funciones explicativa y prescriptiva con otras de menor presencia en los textos instruccionales.

\section{Ejemplo 5}

\section{Limpieza del contenedor}

Después del lavado revise el contenedor y límpielo si hay restos de detergente. Tire con un poco más de fuerza y sáquelo de la lavadora. Límpielo con un cepillo y agua caliente y séquelo. Cuando sea necesario podéis limpiar también la parte interior de la caja del recipiente de dosificación, si dentro de ella están los restos del producto para lavar.

El movimiento 6 se refiere a los problemas de fácil solución, como pueden ser la sustitución de las piezas por otras de repuesto. Este movimiento sólo se aplica a los casos en los que el propio consumidor se debe encargar, por la sencillez de la operación, de la reposición de las piezas gastadas o defectuosas. De no resultar asequible la operación, el cliente debe acudir al servicio técnico.

Sin embargo, antes de acudir a los expertos, también se incluyen otros apartados en los manuales de instrucciones que pueden ser de ayuda al usuario para discernir la causa de una avería real o ficticia. En este grupo se trata de aconsejar al consumidor acerca de las anomalías en el funcionamiento del aparato (falta de funcionamiento, ruidos, vibraciones, problemas de temperatura, etc.), sus posibles causas y las pautas a seguir.

El movimiento llamado Solución de problemas combina la función prescriptiva-explicativa (Utilice, Compruebe) con otras funciones, como la condicional (Si deja de funcionar la lámpara..., desconecte ...).

\section{Ejemplo 6}

\section{Cambio de la lámpara de iluminación}

Si deja de funcionar la lámpara de iluminación del refrigerador, desconecte la clavija de conexión de la base de enchufe y opere como le indica la figura 8 .

Utilice la lámpara fundida como muestra para comprar la nueva.

Compruebe que la potencia no es superior a 15 watios. 
El movimiento 7 se refiere a los apartados de Garantía y servicio técnico, dos epígrafes diferentes que, sin embargo, unimos en un mismo movimiento, ya que se aplican al caso del mantenimiento exterior por parte de expertos. La garantía es una carta de condiciones de revisión gratuita, o parcialmente subvencionada, del electrodoméstico. Entre las mencionadas condiciones se incluye la fecha de compra, el modelo y el número de serie del aparato, y se suele exigir la presentación de la factura de compra y la no manipulación previa por personal no especializado. El apartado de servicio técnico suele incluir un listado de teléfonos y direcciones.

El movimiento llamado Garantía, en contraste con la función semántica prescriptiva-explicativa de los movimientos anteriores, es puramente informativo y describe en presente de indicativo (consiste, incluye) o futuro (se atenderán, deberá) las condiciones del mantenimiento gratuito total o parcial del aparato.

\section{Ejemplo 7}

\section{Normas generales de garantía}

Este aparato ELBE está garantizado por un periodo de seis meses contra todo defecto de fabricación, a partir de la fecha de venta. La garantía consiste en la sustitución gratuita de los componentes. Incluye la mano de obra necesaria para la reposición de las piezas defectuosas en nuestros servicios técnicos oficiales.

Las reparaciones de televisores portátiles en periodo de garantía se atenderán en los talleres del servicio técnico oficial a los que el usuario deberá llevar el aparato averiado.

\section{CONCLUSIONES}

Hemos abordado los mensajes instruccionales por ser un tema poco tratado en artículos sobre análisis del discurso, ya que la mayoría de los estudios académicos sobre género se han centrado en el artículo de investigación desde cualquiera de sus múltiples perspectivas. Creemos que los textos instruccionales deben ser objeto de mayor atención, de cara a la comprensión de sus funciones y movimientos más prototípicos, y, también, con vistas a una producción más clara, lógica y es- 
tructurada. Esta parece ser la clave para disminuir la distancia entre el emisor del mensaje (técnico) y el receptor (lego).

Sin embargo, los manuales de instrucciones suelen ser textos directos que conllevan un estilo carente de ornamentación, constituyendo la terminología de especialidad la única nota oscura con respecto a la comprensión del mensaje de cara a la comprensión de los legos en la materia. Sin embargo, como hemos señalado, algunos mensajes instruccionales muestran un cierto grado de oscuridad, más allá de lo que compete al léxico de especialidad. Pensamos que esto se debe a que muchos de ellos proceden de traducciones torpes y presurosas del inglés, la lengua por excelencia de las comunicaciones técnicas internacionales.

Por otro lado, pensamos que los manuales de instrucciones se encuentran fuera de la influencia del márketing y la publicidad, puesto que estas técnicas se centran en la venta de un producto por sus características externas o internas, y no por el texto instruccional que acompaña al producto en cuestión. Desde este punto de vista, el mencionado género, a diferencia del mensaje publicitario, se muestra neutral y aséptico: no se exhiben fotografías engañosas, sino que el objetivo final de su producción es que prime la sencillez y la claridad, por más que no siempre ocurra así.

El estudio revela que las instrucciones dentro del género de los manuales de manejo de electrodomésticos muestran principalmente el uso de las funciones semánticas de información, explicación y consejo. La función prescriptiva-explicativa suele ser la más habitual y aparece en conjunción con otras funciones como las de propósito, condición, manera, etc.

Las funciones comunicativas aportan el contenido del mensaje y se esclarecen a lo largo de siete movimientos: advertencias, características técnicas, instalación, funcionamiento, limpieza y mantenimiento, solución de problemas y, finalmente, garantía y servicio técnico. Estos movimientos persiguen diferentes finalidades en la transmisión de significado del mensaje, tal y como indican los respectivos nombres que, sin embargo, parecen adecuarse perfectamente a la progresión del mensaje. Así, el comienzo (Advertencias) queda marcado por la función semántica de consejo y precaución, y por el movimiento denominado Caracteristicas técnicas que se corresponde con la función informativa. Pasando a la parte media o mensaje central de los manuales de instrucciones encontramos que los movimientos llamados Instalación, Funcionamiento, Lim- 
pieza y Mantenimiento y Solución de problemas se encuadran dentro de la función prescriptiva-explicativa. Finalmente, el movimiento llamado Garantía y servicio técnico enlaza con la función informativa.

Se establece, por tanto, un avance gradual en la progresión del texto instruccional que oscila del consejo, la precaución y la información en la parte inicial, pasa por la función explicativa en los cuatro movimientos centrales del manual de instrucciones, y desemboca en el mensaje informativo en la parte final. Esta organización garantiza, además del engarce entre función comunicativa y función semántica, la cohesión de funciones entre módulos parejos y una comprensión más fluida del texto instruccional por parte del consumidor.

El conocimiento de las pautas anteriores hace que el lector habitual domine los formulismos de los mensajes instruccionales y sepa cómo discriminar la información necesaria de la superflua.

\section{Bibliografía}

Alarcos, Emilio (1994) Real Academia Española: Gramática de la lengua española. Madrid: Espasa Calpe.

Álvarez-Dardet, C., F Bolúmar y M. Porta-Serra (1987) “Tipos de estudios" en Medicina Clínica 89.

BAILAR, J., T. Louis, P. Lavori y W. Polansky (1984) “A classification for biomedical research reports". The New England Journal of Medicine 31.

CARROLL, T. y J. Delin (1998) "Written instructions in japanese and english: a comparative analysis". Pragmatics 8 (3).

CILIBERTI, Anna (1990) "Instructions for use: a macrotextual and stylistic analysis" en (eds.) Halliday, M. A. K., J. Gibbons y H. Nicholas Learning, Keeping and using language. Selected papers from the $8^{\text {th }}$ World Congress of Applied Linguistics. Amsterdam: John Benjamins.

Delin, J., Hartley, A., Paris, C., Scott, D. y Vander Linden, K. (1994) "Expressing procedural relationships in multilingual instructions". Proceedings of 7th International Workshop on Natural Language Generation. Kennebunkport, Maine.

- Hartley, A. y Scott, D. (1996) "Towards a contrastive pragmatics: syntactic choice in english and french instructions". Language Sciences, 18 (3-4). 
FERNÁNDEZ Lagunilla, Marina (1999) "Las construcciones de gerundio". Real Academia de la Lengua Española: Nueva Gramática descriptiva de la lengua española, vol. 2, editada por Ignacio Bosque y Violeta Demonte, Madrid: Espasa Calpe.

GARRIDO, Joaquín (1999) "Los actos de habla. Las oraciones imperativas”. En Ignacio Bosque y Violeta Demonte (coords.) Gramática descriptiva de la lengua española. Madrid: Espasa Calpe.

MERCADO, Sebastián (2003) "Estructura y relación de poder en los prospectos de medicamentos vendidos en España. Estudios Filológicos 38.

MURCIA, Susana (2000) "The choice of directive expressions in english and spanish instructions: a semantic network". En E. Ventola (ed.) Discourse and community. Doing functional linguistics. Language in performance, 21. Tubingen: Gunter Narr Verlag.

- y Delin, J. (2001) "Expressing the notion of purpose in english and spanish instructions". Functions of Language 8 (1).

- O'Donnell, Michael (2002) "Semantic functions in instructional texts: a comparison between english and spanish" en (eds.) L. Iglesias, y S. Doval Studies in Contrastive Linguistics.

PARIS, C. y Scott, D. (1994) "Stylistic variation in multilingual instructions". Proceedings of 7 th International Workshop on Natural Language Generation. Kennebunkport, Maine.

PUGLIELLI, A. (1990) "Instructions for use: from macro to microlinguistic analysis". Learning, keeping and using language. Selected papers from the $8^{\text {th }}$ World Congress of Applied Linguistics. Amsterdam: John Benjamins.

RAIBLE, Wolfang (2004) “¿Qué es un texto?” en Función 21-24.

TORRES, A. (2003) "Consideraciones sobre la modalidad objetiva en textos técnicos y científicos dentro del campo de la estilística textual" en Las lenguas para fines especificos y la sociedad del conocimiento. Madrid: DLACT de la Universidad Politécnica de Madrid.

VIVANCO, Verónica (2001) "El subgénero de la publicidad industrial y su escala axiológica” en Revista Española de Lingüistica Aplicada 14. 